\title{
Simulating the Pāninian System of Sanskrit Grammar
}

\author{
Anand Mishra \\ Department of Computational Linguistics \\ Ruprecht Karls University, Heidelberg \\ http://sanskrit.sai.uni-heidelberg.de
}

\begin{abstract}
We propose a model for the computer representation of the Pạninian system of sanskrit grammar. Based on this model, we render the grammatical data and simulate the rules of Aștāadhyāyī on computer. We then employ these rules for generation of morpho-syntactical components of the language. These generated components we store in a psubsequential automata. This we use to develop a lexicon on Pāninian principles. We report briefly its implementation.
\end{abstract}

\section{A Representation of Aștādhyāyī}

The general grammatical process of Aștāāhyāȳi (Katre, 1989) can be viewed as consisting of the following three basic steps:

1. Prescription of the fundamental components which constitute the language.

2. Characterization of these fundamental components by assigning them a number of attributes.

3. Specification of grammatical operations based on the fundamental components and their attributes.

\subsection{Fundamental Components}

In his grammar Pāṇini furnishes a number of elements (phonemes/morphemes/lexemes) which constitute the building blocks of the language. We assign each of them a unique key in our database. Thus the phoneme $/ a /$ has the key a_0, the $k r t$ suffix / $a /$ has the key a_3 and the taddhita suffix / $a$ / is represented by the key a_4. Given such a collection of unique keys, we define the set of fundamental components as follows:

Definition 1 The collection of unique keys corresponding to the basic constituents of the language, we define as the set $\mathcal{F}$ of fundamental components.

Further, we decompose this set $\mathcal{F}$ into two disjoint sets $\mathcal{P}$ and $\mathcal{M}$, where $\mathcal{P}$ is the set of keys corresponding to the phonemes and $\mathcal{M}$ containing the keys of the rest of the constituting elements (morphemes/lexemes).

$$
\begin{array}{r}
\mathcal{P}=\left\{\text { a_o }, i_{-} 0, u_{-} 0, \ldots\right\} \\
\mathcal{M}=\{\text { bhU_a, tip_0, laT_o }, \ldots\} \\
\mathcal{F}=\mathcal{P} \cup \mathcal{M} \\
\mathcal{P} \cap \mathcal{M}=\phi
\end{array}
$$

\section{$1.2 \quad$ Attributes}

The fundamental units of the language are given an identity by assigning a number of attributes to them. The various technical terms introduced in the grammar come under this category, as also the it -markers and sigla or pratyāhāras. For example, the attributes hrasva, guna and $a \mathrm{C}$ characterize the element a_0 as short vowel $/ a /$ and attributes like pratyaya, prathama and ekavacana tell that $t i \mathrm{P}$ (= tip_0) is a third-person singular suffix. Again, each attribute is assigned a unique key in our database.

Definition 2 The collection of unique keys corresponding to the terms, which characterize a fundamental component, we define as the set $\mathcal{A}$ of attributes. 
Corresponding to the sets $\mathcal{P}$ and $\mathcal{M}$ we can decompose the set $\mathcal{A}$ into two disjoint sets $\mathcal{A}_{\pi}$ and $\mathcal{A}_{\mu}, \mathcal{A}_{\pi}$ being the set of unique keys of the attributes to the elements of $\mathcal{P}$ and $\mathcal{A}_{\mu}$ to elements of $\mathcal{M}$.

$$
\begin{gathered}
\mathcal{A}_{\pi}=\{\text { hrasva_0, udAtta_0, it_o }, \ldots\} \\
\mathcal{A}_{\mu}=\{\text { dhAtu_0, pratyaya_0, zit_o, } \ldots\} \\
\mathcal{A}=\mathcal{A}_{\pi} \cup \mathcal{A}_{\mu}
\end{gathered}
$$

We note that any two of the four sets $\mathcal{P}, \mathcal{M}, \mathcal{A}_{\pi}, \mathcal{A}_{\mu}$ are mutually disjoint.

\section{Basic Data Structures}

Given the set of fundamental components $(\mathcal{F}=\mathcal{P} \cup \mathcal{M})$ and the set of attributes $(\mathcal{A}=$ $\mathcal{A}_{\pi} \cup \mathcal{A}_{\mu}$ ), we now define our data structure for representing the Pạninian process.

\subsection{Sound Set $\psi$}

Definition $3 A$ sound set $\psi$ is a collection of elements from sets $\mathcal{P}, \mathcal{M}$ and $\mathcal{A}$ having exactly one element from the set $\mathcal{P}$.

$$
\begin{array}{r}
\psi=\left\{\pi_{p}, \mu_{i}, \alpha_{j} \mid \pi_{p} \in \mathcal{P}, \mu_{i} \in \mathcal{M},\right. \\
\left.\alpha_{j} \in \mathcal{A}, i, j \geq 0\right\}
\end{array}
$$

This is an abstract data structure. Although it corresponds to a phoneme or one sound unit, it represents more than just a phoneme.

\subsection{Language Component $\lambda$}

Definition $4 A$ language component $\lambda$ is an ordered collection of at least one or more sound sets.

$$
\lambda=\left[\psi_{0}, \psi_{1}, \psi_{2}, \ldots \psi_{n}\right] \text { such that }\|\lambda\|>0
$$

Convention: We use square brackets [ ] to represent an ordered collection and curly brackets \{\} for an unordered collection.

Language expressions at every level (phonemes, morphemes, lexemes, words, sentences) can now be represented as a language component.

Example 1: We represent the verbal root $b h \bar{u}$ as a language component $\lambda$.

$$
\begin{aligned}
\lambda & =\left[\psi_{1}, \psi_{2}\right] \text { where } \\
\psi_{1} & =\{b h, b h \bar{u}, \text { dhātu, .. }\} \\
\psi_{2} & =\{u, b h \bar{u}, \text { dhātu, udātta, dīrgha, ac }, \ldots\}
\end{aligned}
$$

Corresponding to the two phonemes $b h$ and $\bar{u}$ in $b h \bar{u}$, we have an ordered collection of two sound sets $\psi_{1}$ and $\psi_{2}$. Consider the first one $\psi_{1}$ : Its first element $b h$ is from the phoneme set $\mathcal{P} .{ }^{1}$ The second element $b h \bar{u}$ tells that the phoneme of this sound set is a part of the fundamental unit $b h \bar{u}$. The third element stores the attribute $d h \bar{a} t u$ (verbal root) to this sound set. Similarly, the second sound set $\psi_{2}$ has phoneme attributes which tell it to be an udātta (high pitched) dīrgha (long) $a \mathrm{C}$ (vowel).

Example 2: Similarly, the language component corresponding to the morpheme $l \mathrm{AT}$ is:

$$
\begin{aligned}
\lambda & =[\psi] \text { where } \\
\psi & =\{l, l \text { AT }, \text { pratyaya, ait }, \text { tit }, \ldots\}
\end{aligned}
$$

Attribute tit says that it has $t$ as $i t$ - marker.

Example 3: The morphemes bhu followed by $l$ AT can now be represented together by the language component

$$
\begin{aligned}
& \lambda=\left[\psi_{1}, \psi_{2}, \psi_{3}\right] \text { where } \\
& \psi_{1}=\{b h, b h \bar{u}, d h \bar{a} t u, \ldots\} \\
& \psi_{2}=\{u, b h \bar{u}, \text { dhātu, udātta, dīrgha, } a \mathrm{C}, \ldots\} \\
& \psi_{3}=\{l, l \text { AṬ, pratyaya, ait }, \underline{t i t}, \ldots\}
\end{aligned}
$$

Different linguistic units can now be identified by carrying out intersection with the appropriate subsets of $\mathcal{P}, \mathcal{M}$ and $\mathcal{A}$. For example to get the verbal root or dhätu in $\lambda$ we take the intersection of an identity set $\iota=\{d h \bar{a} t u\}$ with each of $\psi_{i}$ 's in $\lambda$ and store the index $i$ when the intersection-set is not empty. In this case we get the index list $[1,2]$. The list of $\psi_{i}$ 's corresponding to these indices then gives the searched morpheme. Thus, the verbal root is given by the language component $\left[\psi_{1}, \psi_{2}\right]$.

\subsection{Process Strip $\sigma$}

Definition 5 A process strip $\sigma$ is an ordered collection of pairs, where the first element of the pair is the number of a particular grammatical rule (e.g. rule $_{p}$ ) and the second element is a language component $\lambda$.

$$
\sigma=\left[\left(\operatorname{rule}_{p}, \lambda_{p}\right),\left(\text { rule }_{q}, \lambda_{q}\right), \ldots\right]
$$

The rule number corresponds to the Aș̣āadhyāȳ order and binds the process

\footnotetext{
${ }^{1}$ Actually, it is the unique key bh_0 corresponding to the phoneme $b h$ which is stored in the sound set.
} 
strip with a function implementing that rule in the actual program. Thus, the process strip simulates the Pạninian process by storing in the language component $\lambda_{p}$ the effect of applying the rule rule $_{p}$.

\section{Basic Operations}

Having defined our data-structure, we now introduce the basic operations on them.

\subsection{Attribute Addition}

Let $\alpha \subset \mathcal{A} \cup \mathcal{M}$ and $\psi$ be a sound set. Then attribute addition is defined as

$$
h_{a \psi}(\psi, \alpha)=\psi \cup \alpha
$$

This operation can be applied to a number of sound sets given by indices $[i, i+1, \ldots, j]$ in a given language component $\lambda$

$$
\begin{array}{r}
h_{a \lambda}(\lambda, \alpha,[i, \ldots, j])=\left[\psi_{1}, \ldots, \psi_{i} \cup \alpha, \ldots,\right. \\
\left.\psi_{j} \cup \alpha, \ldots, \psi_{n}\right]
\end{array}
$$

Example 4: Consider the language component corresponding to the morpheme śaP

$$
\begin{aligned}
\lambda & =[\psi] \text { where } \\
\psi & =\{a, \text { śaP }, \text { pratyaya, śit, pit }, \ldots\}
\end{aligned}
$$

Rule tin śit sārvadhātukam (3.4.113) says that affixes in the siglum $t i \dot{\mathrm{N}}$ and those having $s$ as it marker are assigned the attribute sārvadhātuka. We implement this rule by checking if there are sound sets with attributes pratyaya together with $t i \dot{\mathrm{N}}$ or sit and adding the attribute sārvadhātuka if the condition is fulfilled. In this case, we get:

$$
\begin{aligned}
\lambda & =[\psi] \text { where } \\
\psi & =\{a, \text { śaP, pratyaya, śit, pit, sārvadhātuka }\}
\end{aligned}
$$

\subsection{Augmentation}

Let

$$
\begin{aligned}
& \lambda=\left[\psi_{1}, \ldots, \psi_{i}, \psi_{i+1}, \ldots, \psi_{n}\right] \\
& \lambda_{k}=\left[\psi_{1 k}, \psi_{2 k}, \psi_{3 k}, \ldots, \psi_{m k}\right]
\end{aligned}
$$

and $i$ be an integer index such that $i \leq\|\lambda\|$, then augmentation of $\lambda$ by $\lambda_{k}$ at index $i$ is defined as

$$
\begin{array}{r}
h_{g}\left(\lambda, \lambda_{k}, i\right)=\left[\psi_{1}, \ldots, \psi_{i}, \psi_{1 k}, \psi_{2 k}, \psi_{3 k}, \ldots\right. \\
\left.\psi_{m k}, \psi_{i+1}, \ldots, \psi_{n}\right]
\end{array}
$$

Example 5: Consider the language component $\lambda$ corresponding to the verbal root $b h \bar{u}$.

$$
\begin{aligned}
\lambda & =\left[\psi_{1}, \psi_{2}\right] \text { where } \\
\psi_{1} & =\{b h, b h \bar{u}, \text { dhātu, .. }\} \\
\psi_{2} & =\{u, b h \bar{u}, \text { dhātu, udātta, dīrgha, ac }, \ldots\}
\end{aligned}
$$

RulE vartamāne lat (3.2.123) says that the morpheme $l \mathrm{AT}$ is added after a dhātu if the present action is to be expressed. To implement this rule, we first look for the indices of sound sets which have the attribute $d h \bar{a} t u$ and then append the sound set corresponding to $l$ AṬ after the last index. We get,

$$
\begin{aligned}
& \lambda=\left[\psi_{1}, \psi_{2}, \psi_{3}\right] \text { where } \\
& \psi_{1}=\{b h, b h \bar{u}, d h \bar{a} t u, \ldots\}
\end{aligned}
$$

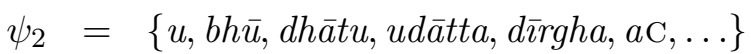

$$
\begin{aligned}
& \psi_{3}=\{l, l \text { AT }, \text { pratyaya, ait }, \text { tit }, \ldots\}
\end{aligned}
$$

\subsection{Substitution}

We define substitution in terms of the above two operations.

Let $[i, i+1, i+2, \ldots, j]$ be the indices of sound sets to be replaced in the language component $\lambda=\left[\psi_{1}, \ldots, \psi_{i}, \psi_{i+1}, \ldots, \psi_{n}\right]$.

Let $\lambda_{k}=\left[\psi_{1 k}, \psi_{2 k}, \psi_{3 k}, \ldots, \psi_{m k}\right]$ be the replacement, then the substitution is defined as

$$
\begin{array}{r}
h_{s}\left(\lambda, \lambda_{k},[i, \ldots, j]\right)= \\
h_{g}\left(h_{a \lambda}(\lambda,\{\delta\},[i, \ldots, j]), \lambda_{k}, j\right)
\end{array}
$$

where $\delta \in \mathcal{A}$ is the attribute which says that this sound set is no more active and has been replaced by some other sound set.

Example 6: Consider the language component corresponding to the verbal root $n \bar{\imath} \tilde{\mathrm{N}}$

$$
\begin{aligned}
& \lambda=\left[\psi_{1}, \psi_{2}\right] \text { where } \\
& \psi_{1}=\{n, n \underline{n} \tilde{\mathrm{N}}, d h \bar{a} t u, \tilde{n} i t\} \\
& \psi_{2}=\{i, n \bar{\imath} \tilde{\mathrm{N}}, d h \bar{a} t u, \tilde{n} i t, d \bar{\imath} r g h a, a \mathrm{C}\}
\end{aligned}
$$

RuLE nah nah (6.1.065) says that the initial retroflex $n$ of a dhâtu is replaced by dental $n$. To implement this rule we first search the sound sets corresponding to $d h \bar{a} t u$, check whether the first one has a retroflex $n$ and if the conditions are fulfilled, add the attribute $\delta$ in that sound set and append the sound set corresponding to $n$ after it. Further we 
transfer all attributes (except the phoneme attributes) from the $n$ - sound set to $n$ - sound set for sthānivadbhāva. We get,

$$
\begin{aligned}
& \lambda=\left[\psi_{1}, \psi_{2}, \psi_{3}\right] \text { where } \\
& \psi_{1}=\{n, n \underline{\tilde{\mathrm{N}}} \tilde{\mathrm{N}}, d h \bar{a} t u, \tilde{n} i t, \delta\} \\
& \psi_{2}=\{n, n \underline{\overline{\mathrm{N}}} \mathbf{\mathrm { N }}, d h \bar{a} t u, \tilde{n} i t\} \\
& \psi_{3}=\{i, n \underline{\imath} \tilde{\mathrm{N}}, d h \bar{a} t u, \tilde{n} i t, d \bar{\imath} r g h a, a \mathrm{C}\}
\end{aligned}
$$

\section{Grammatical Process}

\subsection{Representing a Rule of Grammar}

We represent a rule of grammar through a function $f_{q}$, which takes a process strip $\sigma_{p}$ and adds a new pair $\left(\right.$ rule $\left._{q}, \lambda_{q}\right)$ to it where rule $_{q}$ is the number of the present rule and $\lambda_{q}$ is the new modified language component after application of one or more of the three operations defined above on the input language component $\lambda_{p}$.

$$
\begin{aligned}
f_{q}\left(\sigma_{p}\right) & =\sigma_{q} \text { where } \\
\sigma_{p} & =\left[\ldots,\left(\text { rule }_{p}, \lambda_{p}\right)\right] \\
\sigma_{q} & =\left[\ldots,\left(\text { rule }_{p}, \lambda_{p}\right),\left(\text { rule }_{q}, \lambda_{q}\right)\right] \\
\lambda_{q} & =h_{a}, h_{g}, h_{s}\left(\lambda_{p}, \ldots\right)
\end{aligned}
$$

\subsection{Structure of a rule}

The general structure of a rule is as follows:

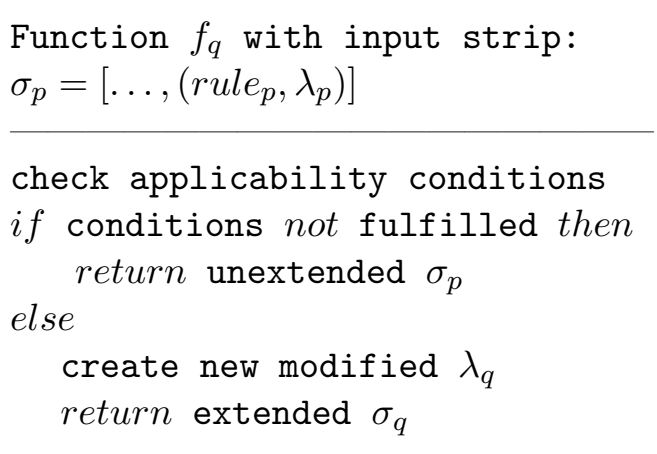

Thus, given a particular state (represented by $\sigma_{p}$ ) in the process of generation, the system provides for checking the applicability of a rule $f_{q}$, and if the conditions are fulfilled, the rule is applied and the changed language component together with the rule number is stored in the modified state (represented by $\sigma_{q}$ ).

As the rule numbers are also stored, we can implement the rules of trip $\bar{a} d \bar{\imath}$ and make their effects invisible for subsequent applications. The order in which rules are applied is provided manually through templates.

\section{Example}

We take a verbal root $b h \bar{u}$ and generate the final word bhavati meaning "he/she/it becomes". We initialize the process strip $\sigma_{0}$ by loading the language component corresponding to the verbal root and adding $a 00000$ as the rule number.

$$
\begin{aligned}
& \sigma_{0}=\left[\left(a 00000, \lambda_{0}\right)\right] \text { where } \\
& \lambda_{0}=\left[\psi_{0 a}, \psi_{0 b}\right] \text { with } \\
& \psi_{0 a}=\{b h, b h \bar{u}, d h \bar{a} t u\} \\
& \psi_{0 b}=\{u, b h \bar{u}, \text { dhātu, dìrgha, udātta\} }
\end{aligned}
$$

Rule vartamāne lat (3.2.123) says that the morpheme $l \mathrm{~A}$ T is added after a dhātu if the present action is to be expressed. The application now involves following steps: Look in the last language component $\lambda$ of the process-strip $\sigma$. If there are sound sets $\psi$ with the identity set $\iota=\{d h \bar{a} t u\}$ in it, get their indices in index list. This returns the index list $[1,2]$. If index list is non empty then augment the language component $\lambda_{0}$ by attaching the language component corresponding to the morpheme $l \mathrm{AT}$. This is attached in this case at index 2 as the new morpheme comes after dhätu. Extend the process strip $\sigma_{0}$ accordingly.

$$
f_{a 32123}\left(\sigma_{0}\right)=\sigma_{1}
$$

$$
\begin{aligned}
& \sigma_{1}=\left[\left(a 00000, \lambda_{0}\right),\left(a 32123, \lambda_{1}\right)\right] \text { where } \\
& \lambda_{1}=\left[\psi_{0 a}, \psi_{0 b}, \psi_{1 a}\right] \text { with } \\
& \psi_{0 a}=\{b h, b h \bar{u}, d h \bar{a} t u\}
\end{aligned}
$$

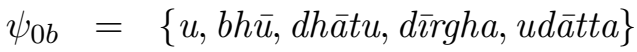

$$
\begin{aligned}
& \psi_{1 a}=\{l, l \text { AṬ, pratyaya, ait, tit }\}
\end{aligned}
$$

RULE tip tas jhi sip thas tha mip vas mas ta âtām jha thās âthām dhvam iṭ vahi mahin (3.4.078) provides for substitution of $l$ AT . We take the first suffix $t i \mathrm{P}$ for replacement. The sound sets to be replaced are determined by taking intersection with the set $\left\{l \mathrm{AT}, l_{\mathrm{IT}}, l_{\mathrm{O}} \mathrm{T}\right.$, ... $\}$ which has the morphemes having cover term $l$. In this case it is at the index 3 . We replace this sound set with $t i \mathrm{P}$ i.e. add the attribute $\delta$ to the sound set at index 3 and augment the language component at this index.

$$
f_{a 34078}\left(\sigma_{1}\right)=\sigma_{2}
$$




$$
\begin{aligned}
& \sigma_{2}=\left[\ldots,\left(a 32123, \lambda_{1}\right),\left(a 34078, \lambda_{2}\right)\right] \\
& \lambda_{2}=\left[\psi_{0 a}, \psi_{0 b}, \psi_{1 a}, \psi_{2 a}, \psi_{2 b}\right] \\
& \psi_{0 a}=\{b h, b h \bar{u}, d h \bar{a} t u\} \\
& \psi_{0 b}=\{u, b h \bar{u}, \text { dhātu, dīrgha, udātta }\} \\
& \psi_{1 a}=\{l, \text { lAT, pratyaya, ait, tit }, \delta,\} \\
& \psi_{2 a}=\{t, \text { ti } \mathrm{P}, \text { pratyaya, sārvadhātuka, pit }\} \\
& \psi_{2 b}=\{i, t i \mathrm{P}, \text { pratyaya, sārvadhātuka, pit }\}
\end{aligned}
$$

RULE kartari śap (3.1.068) says that the morpheme śaP is added after dhātu but before sārvadhätuka suffix and denotes agent. Check if sound set with sārvadhātuka follows one with $d h \bar{a} t u$. If yes then augment the language component for śaP after dhātu.

$$
\begin{aligned}
& f_{a 31068}\left(\sigma_{2}\right)=\sigma_{3} \\
& \sigma_{3}=\left[\ldots,\left(a 34078, \lambda_{2}\right),\left(a 31068, \lambda_{3}\right)\right] \\
& \lambda_{3}=\left[\psi_{0 a}, \psi_{0 b}, \psi_{3 a}, \psi_{1 a}, \psi_{2 a}, \psi_{2 b}\right] \\
& \psi_{0 a}=\{b h, b h \bar{u}, d h \bar{a} t u\} \\
& \psi_{0 b}=\{u, b h \bar{u}, \text { dhātu, dìrgha, udātta }\} \\
& \psi_{3 a}=\{a, \text { ŚaP, pratyaya, hrasva, sit, pit }\} \\
& \psi_{1 a}=\{l, l \mathrm{AT}, \text { pratyaya, ait, tit, } \delta\} \\
& \psi_{2 a}=\{t, t i \mathrm{P}, \text { pratyaya, sārvadhātuka, pit }\} \\
& \psi_{2 b}=\{i, \text { ti } \mathrm{P}, \text { pratyaya, sārvadhātuka, pit }\}
\end{aligned}
$$

RULE yasmāt pratyaya vidhis tad ādi pratyaye angam (1.4.013) makes the part before the suffix ś $a \mathrm{P}$ an anga with respect to it.

$$
f_{a 14013}\left(\sigma_{3}\right)=\sigma_{4}
$$

$$
\begin{aligned}
& \sigma_{4}=\left[\ldots,\left(a 31068, \lambda_{3}\right),\left(a 14013, \lambda_{4}\right)\right] \\
& \lambda_{4}=\left[\psi_{0 a}, \psi_{0 b}, \psi_{3 a}, \psi_{1 a}, \psi_{2 a}, \psi_{2 b}\right] \\
& \psi_{0 a}=\{b h, b h \bar{u}, \text { dhātu, ainga }\}
\end{aligned}
$$

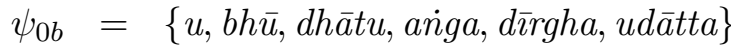

$$
\begin{aligned}
& \psi_{3 a}=\{a, \dot{\mathrm{S}} a \mathrm{P}, \text { pratyaya, hrasva, sit, pit }\} \\
& \psi_{1 a}=\{l, \text { lAT, pratyaya, ait, tit }, \delta\} \\
& \psi_{2 a}=\{t, t i \mathrm{P}, \text { pratyaya, sārvadhātuka, pit }\} \\
& \psi_{2 b}=\{i, t i \mathrm{P}, \text { pratyaya, sārvadhātuka, pit }\}
\end{aligned}
$$

RuLE sārvadhātuka ārdhadhātukayoh (7.3.084) says that before sārvadhātuka or $\bar{a}$ rdhadhātuka replace the $i \mathrm{~K}$ vowels by guna vowels. As ŚaP is sārvadhātuka, we get

$$
f_{a 73084}\left(\sigma_{4}\right)=\sigma_{5}
$$

$$
\begin{aligned}
& \sigma_{5}=\left[\ldots,\left(a 14013, \lambda_{4}\right),\left(a 73084, \lambda_{5}\right)\right] \\
& \lambda_{5}=\left[\psi_{0 a}, \psi_{0 b}, \psi_{5 a}, \psi_{3 a}, \psi_{1 a}, \psi_{2 a}, \psi_{2 b}\right] \\
& \psi_{0 a}=\{b h, b h \bar{u}, d h \bar{a} t u, a \dot{n} g a\}
\end{aligned}
$$

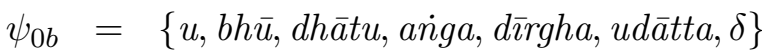

$$
\begin{aligned}
& \psi_{5 a}=\{o, b h \bar{u}, \text { dhātu, anga }\} \\
& \psi_{3 a}=\{a, \text { śa } \mathrm{P}, \text { pratyaya, hrasva, sit }, \text { pit }\} \\
& \psi_{1 a}=\left\{l, l_{\mathrm{AT}}, \text { pratyaya, ait }, \underline{t i t}, \delta\right\} \\
& \psi_{2 a}=\{t, t i \mathrm{P}, \text { pratyaya, sārvadhātuka, pit }\} \\
& \psi_{2 b}=\{i, t i \mathrm{P}, \text { pratyaya, sārvadhātuka, pit }\}
\end{aligned}
$$

RULE ec ah ay av āy āv ah (6.1.078) says that before $a \mathrm{C}$ (vowel) $e, o, a i, a u$ are respectively replaced by ay, av, $\bar{a} y, \bar{a} v$.

$$
f_{a 61078}\left(\sigma_{5}\right)=\sigma_{6}
$$

$$
\begin{aligned}
& \sigma_{6}=\left[\ldots,\left(a 73084, \lambda_{5}\right),\left(a 61078, \lambda_{6}\right)\right] \\
& \lambda_{6}=\left[\psi_{0 a}, \psi_{0 b}, \psi_{5 a}, \psi_{6 a}, \psi_{6 b}, \psi_{3 a}, \psi_{1 a}, \psi_{2 a}, \psi_{2 b}\right] \\
& \psi_{0 a}=\{b h, b h \bar{u}, \text { dhātuainga }\}
\end{aligned}
$$

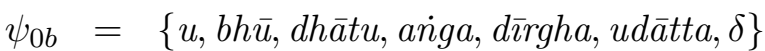

$$
\begin{aligned}
& \psi_{5 a}=\{o, b h \bar{u}, \text { dhātu, ainga, } \delta\} \\
& \psi_{6 a}=\{a, a v, b h \bar{u}, \text { dhātu, àiga, hrasva }\} \\
& \psi_{6 b}=\{v, a v, b h \bar{u}, \text { dhātu, àiga }\} \\
& \psi_{3 a}=\{a, \dot{\mathrm{S}} a \mathrm{P}, \text { pratyaya, hrasva, sit, pit }\} \\
& \psi_{1 a}=\{l, \text { lAT, pratyaya, ait, tit, } \delta\} \\
& \psi_{2 a}=\{t, \text { ti } \mathrm{P}, \text { pratyaya, sārvadhātuka, pit }\} \\
& \psi_{2 b}=\{i, \text { ti } \mathrm{P}, \text { pratyaya, sārvadhātuka, pit }\}
\end{aligned}
$$

Finally we collect all $\psi_{i}$ s not having a $\delta$, i.e. which are not already replaced. This gives us the desired form bhavati.

\section{PaSSim (Pāṇinian Sanskrit Simulator)}

In the following we give a brief description of PaSSim (Pāninian Sanskrit Simulator) we are developing at the University of Heidelberg. ${ }^{2}$ The program aims towards developing a lexicon on Pāninian principles. The user enters an inflected word or pada and the system furnishes a detailed, step by step process of its generation. It is written in Python ${ }^{\mathrm{TM}}$ and consists of the following modules (See Figure 1):

\subsection{Database}

This module is for inputting, updating, enhancing and organizing the primary database

\footnotetext{
${ }^{2}$ http://sanskrit.sai.uni-heidelberg.de
} 


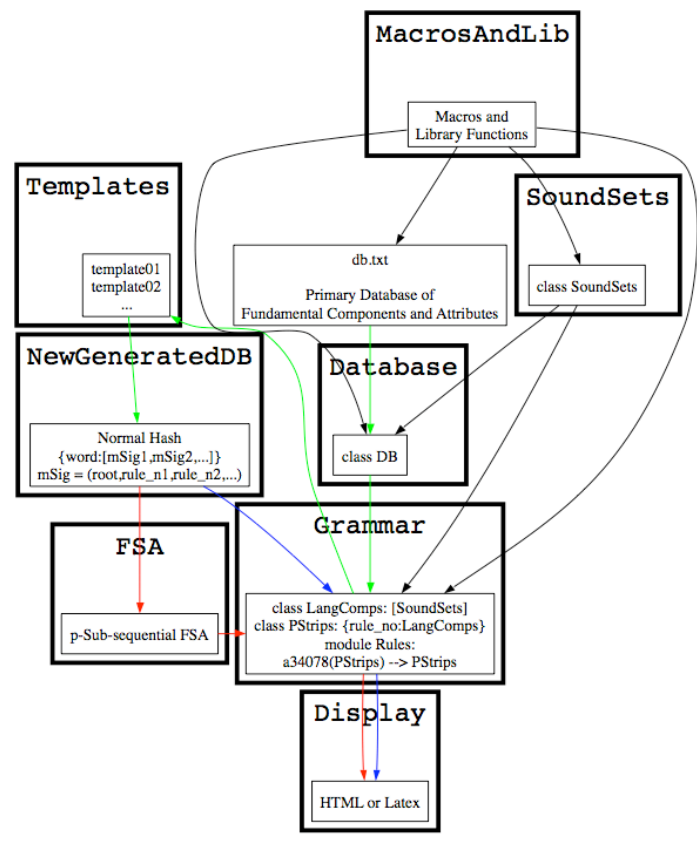

Figure 1: PaSSim (Pāṇinian Sanskrit Simulator)

of fundamental components and attributes. The organization of database serves the purpose of incorporating static information of Pāninian formulations. For example, $u \dot{\mathrm{N}}$ is stored with static attributes dhātu, bhvādi, anit and that its second phoneme is it - marker etc. Thus, the effect of many definition rules of Asțādhyāyī are stored in the database. The database is in ASCII and each fundamental component or attribute has a unique key corresponding to which is a hash.

\subsection{Grammar}

This is the main module. It contains abstract classes corresponding to SoundSets, LanguageComponents and ProcessStrips. Further it has a number of functions like a61065(), which simulate the individual rules of Aștāadhyāyī.

\subsection{Templates}

This module is to organize the prakriy $\bar{a}$. A template prescribes the rules in order of applicability for a group of primary verbs or nominal stems. Templates are specified manually, taking into account the prakriy $\bar{a}$ texts e.g. Siddhānta-Kaumud̄̄ (Vasu, 1905). ${ }^{3}$ It uses

\footnotetext{
${ }^{3}$ We would like to acknowledge two texts in Hindi Vyākaraṇacandrodaya (Śāstrī, 1971) and Aṣṭādhyāyī
}

Grammar to generate the morpho-syntactic word forms or padas.

\subsection{FSA}

This module is for the sake of effecient representation of generated words together with the initializing fundamental component(s) and list of rule numbers. These are stored as a psubsequential transducer (Mohri, 1996). ${ }^{4}$ The output string associated with a word, thus provides the initializing fundamental components and a list of rules. Grammar applies these rules one after another and outputs the final as well as intermediate results.

\subsection{Display}

This module provides HTML 5 / ATEX output. It outputs the content according to the given style sheet for conventions regarding script, color-scheme etc. The phonological, morphological, syntactical and semantical information gathered during the process of generation is rendered in modern terms through a mapping of Pāninian attributes corresponding to it.

\section{References}

Böhtlingk, Otto von. 1887. Pānini's Grammatik. Olms, Hildesheim. Primary source text for our database.

Dīkṣita, Puṣpā. 2006-07. Așțādhyāȳ̄ sahajabodha. Vols. 1-4. Pratibha Prakashan, Delhi, India.

Katre, Sumitra M. 1989. Aștādhyāȳ of Pāninini. Motilal Banarsidass, Delhi, India.

Mohri, Mehryar. 1996. On some Applications of Finite-State Automata Theory to Natural Language Processing. Journal of Natural Language Engineering, 2:1-20.

Śāstrī, Cārudeva. 1971. Vyākaranacandrodaya. Vols. 1-5. Motilal Banarsidass, Delhi, India.

Vasu, Srisa Chandra and Vasu, Vaman Dasa. 1905. The Siddhānta-Kaumudī of Bhațtojī Dīkșita. Vols. 1-3. Panini Office, Bhuvanesvara Asrama, Allahabad, India. Primary source text for prakriyā.

sahajabodha (Dīkṣita, 2006) — which have been very beneficial to us.

${ }^{4}$ Sequential transducers can be extended to allow a single additional output string (subsequential transducers) or a finite number $p$ of output strings ( $p$ - subsequential transducers) at final states. These allow one to deal with the ambiguities in natural language processing (Mohri, 1996).

${ }^{5}$ See: http://sanskrit.sai.uni-heidelberg.de 